\title{
Feasibility of Replacing Sucrose by Sorbitol and Adding Maltodextrin with Nigella Sativa on the Physicochemical and Sensory Properties of Dark Chocolate
}

\author{
Sousan Karimi \\ Department of Food Science and Technology, Faculty of Agriculture, Isfahan Branch, Islamic Azad University, Isfahan, Iran \\ Email address: \\ s. karimistd.iaushk.ac.ir \\ To cite this article: \\ Sousan Karimi. Feasibility of Replacing Sucrose by Sorbitol and Adding Maltodextrin with Nigella Sativa on the Physicochemical and \\ Sensory Properties of Dark Chocolate. International Journal of Nutrition and Food Sciences. Vol. 10, No. 2, 2021, pp. 54-58. \\ doi: $10.11648 /$ j.ijnfs.20211002.13
}

Received: January 14, 2021; Accepted: February 7, 2021; Published: April 29, 2021

\begin{abstract}
Today, one of the problems caused by chocolate consumption is its high sugar and fat content. Therefore, in the present study, the possibility of replacing sucrose with sorbitol and maltodextrin with Nigella Sativa to produce low-calorie dark chocolate will be investigated. To prepare low-calorie dark chocolate, sorbitol was used in four levels $(0,10,20,30 \%)$ and Nigella Sativa on in four levels $(0,3,6,9 \%)$. The effect of different levels of replacement of these compounds on some chemical properties (moisture, fat, protein, carbohydrates, ash), texture (hardness), color (indices L*, a*, b*) and sensory (color, Taste, mouthfeel, and general acceptance) were assessed. Statistical analysis was presented using SPSS 16 software as a completely randomized design. The results showed that significant difference was observed in the fat, protein, carbohydrate, and ash content of the samples containing sorbitol. Samples with higher levels of sorbitol replacement had higher moisture content and lower tissue hardness. The reduction of sucrose had no significant effect on the sensory properties of chocolate samples. As the levels of Nigella Sativa substitution increased, the moisture, fat, and carbohydrate content decreased, and the protein, ash, and texture hardness of the chocolate samples increased. Sensory characteristics, including oral sensation and general acceptance, decreased significantly with increasing levels of Nigella Sativa replacement. The results of color parameter analysis also showed that by increasing the percentage of Nigella Sativa on substitution in the chocolate formulation, the amount of $\mathrm{L}^{*}$ component was reduced and the amount of $\mathrm{a}^{*}$ and $\mathrm{b}^{*}$ components was increased. According to the results of this study, the best sample in terms of chemical, textural and sensory properties of chocolate was produced with $10-20 \%$ replacement of sugar with sorbitol and 3-6\% replacement of maltodextrin with Nigella Sativa.
\end{abstract}

Keywords: Sucrose, Sorbitol, Nigella Sativa, Bitter Chocolate, Low Calorie

\section{Introduction}

As public awareness of the role of nutrition in human health increases, so does the demand for low-calorie foods that can reduce the risk of certain cardiovascular diseases, obesity, diabetes, high blood pressure, and tooth decay increased. From a nutritional point of view, proteins, fats, and carbohydrates are the main factors in the production of calories, and therefore to reduce the calories of food, their reduction in fat and carbohydrates is often examined. Chocolate is a high-calorie food with a fast metabolism and good digestion, and unique taste and texture and the feeling of pleasure after eating it are the reasons for its popularity among all age groups. One of the major problems in consuming this food is its high level of sugar (about 35-35\%) and fat, as well as its high caloric content. Therefore, continuous and long-term consumption of chocolate can cause problems for human health [1]. Sugar and fat are among the high-calorie compounds and on the other hand, are the factors that affect the acceptance of chocolate. Therefore, appropriate compounds should be used as alternatives to compensate for their deficiency in the chocolate formulation, so that in addition to producing a healthier product, an acceptable flavor, texture and appearance can be achieved [2]

Foods containing alcoholic sugars such as sorbitol, 
mannitol, and propylene glycol are known as low-calorie foods. Sugar alcohols have fewer calories than sucrose and have benefits such as reduced glycemic response, reduced tooth decay, and increased probiotic effects. Sugar alcohols have a low rate of metabolism and their absorption in the body is incomplete, therefore, due to incomplete metabolism and fermentation and production of short-chain fatty acids and gas in the body, they produce less energy and blood glucose levels. They are kept low in people with diabetes [3].

Today, modified starch derivatives are widely used in the food industry. Maltodextrin is one of the most well-known fat substitutes obtained by enzymatic or chemical hydrolysis of starch. Maltodextrin is composed of oligomers or D-glucose polymers with $(1,4) \alpha$ bonding. Maltodextrin contains linear amylose and amylopectin, a branch that contains oligosaccharides to polysaccharides based on molecular weight and has a dextrose (DE) equivalent of less than 20 Maltodextrin is more soluble in water than starch and lacks a sweet taste. This compound is used as a low-calorie additive, to improve the gelling, thickening, texture-building properties, increasing viscosity, increasing high-temperature resistance, increasing dry matter content, preventing crystallization, and controlling freezing temperature (Dosic). [4]

Nigella Sativa (Nigella Sativa L.) is a dicotyledonous, herbaceous, annual plant belonging to the Alagan family that is native to West Asia and is compatible with arid regions. Nigella Sativa contains protein (23\%), fat (35-35\%), carbohydrates (often in the form of glucose, xylose, rhamnose, arabinose), vitamins, and minerals. Nigella Sativa is a rich source of essential fatty acids and unsaturated fatty acids including oleic acid and linoleic acid. Compounds such as carotene, potassium, calcium, iron, and phospholipids are also present in Nigella Sativa [5] Nigella Sativa is one of the best sources of natural antioxidants such as alkaloids, phytosterols, tocopherols, flavonoids, and tannins. This medicinal plant has anti-oxidant, anti-inflammatory effects, and Nigella Sativa also strengthens the immune system, lowers blood sugar, blood pressure, expels bile and uric acid, and protects liver and kidney tissues. Antimicrobial and antiparasitic effects have also been reported from this plant [6] The results of research showed that cookie calories were reduced by replacing sucrose with sorbitol, fructose, and mannitol. The lowest energy was observed in cookies prepared with $75 \%$ fructose and $25 \%$ sucrose, and the highest energy was observed in the control sample. reduction in sponge cake calories by replacing sucrose with erythritol. In a study on the effect of sucrose replacement with inulin in the chocolate formula, the results showed improved flow properties and sensory properties of chocolate samples, and replacement of inulin with $20 \%$ of formula sugar had a positive effect on The parameters that determine the quality and consumer acceptance in chocolate were created and due to the nutritional benefits and improvement of physical properties, its use in the chocolate formulation was suggested [7]. The present study aimed to investigate the possibility of replacing sucrose with sorbitol and maltodextrin with Nigella Sativa in the chocolate formulation and low-calorie chocolate production, and the effect of these compounds on some chemical, textural and sensory properties of chocolate.

\section{Materials and Methods}

\subsection{Raw Materials}

Cocoa powder was purchased from Delfi (Malaysia), cocoa butter from Cargill (Malaysia), listin from ADM USA, sucrose from Naghsh Jahan (Iran), maltodextrin from Dextrose Iran (Iran), and Nigella Sativa from a local store. Other chemicals used in this study were obtained from the German company Merck Chemicals.

\subsection{Method of Preparing Chocolate}

For the preparation of chocolate, the formula of $27.5 \%$ cocoa butter, 33\% cocoa powder, 30\% sucrose, 9\% maltodextrin, and $0.50 \%$ listin was used as an emulsifier. First, the cocoa butter was melted in an oven (Memmert UFE500, made in Germany) at $60^{\circ} \mathrm{C}$. Cocoa powder, a sugar substitute containing sorbitol and maltodextrin, was then added to the melted cocoa butter. The resulting mixture was mixed with a mixer at $50 \mathrm{rpm}$ for 4 hours in a paraffin bath $\left(65^{\circ} \mathrm{C}\right)$. The rest of the cocoa butter and listin were added in the final 30 minutes of kneading. The prepared chocolates were stored in a greenhouse at $50^{\circ} \mathrm{C}$ for 24 hours. Then their temperature was raised to $45^{\circ} \mathrm{C}$ and kept at this temperature for 30 minutes. Tempering and molding operations were performed and the molded chocolates were stored in aluminum foil and refrigerated until the experiments were performed [8]

\subsection{Measurement of Some Chemical Properties of Chocolate}

Moisture was measured according to AOAC method No. 1077-97 by Karl Fischer method, fat according to AOAC method number 15-963 by Soxhlet method, protein (caldal), carbohydrate, and ash according to Iranian national standard No. 608.

\subsection{Assessing Tissue Hardness}

To measure the hardness of chocolate samples, first, rectangular chocolate samples with dimensions of $8 \times 20 \times 8$ $\mathrm{mm}$ were prepared. Texture test was performed using a histometer (H50KS model manufactured by Hounsfield UK), equipped with a flat bottom probe with a diameter of $1.6 \mathrm{~mm}$ and a penetration rate of $1.5 \mathrm{~mm} / \mathrm{s}$. The maximum force required to penetrate to a depth of $6 \mathrm{~mm}$ was reported as an index of stiffness in terms of Newton [9]

\subsection{Color Evaluation}

To evaluate the color of chocolate samples, the Hunterleb colorimeter (model CR-410 made in Minolta, Japan) was used and evaluation of factors $\left(\mathrm{L}^{*}\right),\left(\mathrm{a}^{*}\right)$ and $\left(\mathrm{b}^{*}\right)$ were used. The $\mathrm{L}^{*}$ indicator indicates the brightness of the sample and its range varies from zero (black) to 100 (white). The $a^{*}$ Indicates degree of redness (red to green) and $b^{*}$ degree of 
yellowing (yellow to blue) [9].

\subsection{Sensory Evaluation}

Sensory characteristics of the sample including color, flavor, mouthfeel, and general acceptability by 15 trained evaluators using the five-point hedonic method $(1$ = very bad, $2=$ bad, $3=$ moderate, $4=$ good, and $5=$ Very good) was evaluated. Each sample was randomly assigned a three-digit code and the samples were randomly provided to the evaluators [10]

\subsection{Statistical Analysis}

Comparison of the effect of sucrose replacement by sorbitol and maltodextrin with Nigella Sativa on chemical, textural and sensory properties of diet dark chocolate and comparison with the control sample using NOVA analysis of variance in a completely randomized design and comparing the mean of treatments Duncan polynomial test at 5\% probability level using SPSS software. 16 done. Graphs were drawn by Excel 2007 software.

\section{Results and Discussion}

\subsection{The Effect of Sucrose Replacement with Sorbitol and Maltodextrin with Nigella Sativa on Some Chemical Properties of Chocolate}

\subsubsection{Humidity}

Moisture is the amount of free and continuous water in the texture of food, so this index in food plays an important role in the crispness and shelf life of products. According to the results, it was found that with increasing levels of sucrose replacement with sorbitol and Maltodextrin increased and decreased moisture content with Nigella Sativa. Sugar alcohol such as sorbitol, propylene glycol, and glycerin is a hygroscopic compound and therefore play an important role in the moisture content of the food. Due to the presence of hydrophilic chains in their structure, such as hydroxyl and carboxyl groups, these compounds have a great effect on the absorption of food moisture. Sorbitol lost less moisture due to its ability to retain moisture during kneading operations, and samples containing high percentages of it had higher moisture content. The results obtained in the present study are consistent with the findings. The researchers observed a higher moisture content in low-fat cookie samples containing inulin and sugar-substituted tagatose. Maltodextrin is also a moisture-absorbing substance which, due to its high competition with other compounds for water absorption, and its amylose and amylopectin chain structure and hydrophilic head, largely prevents its release and evaporation, which leads to softness. Wetting of samples containing high ratios of maltodextrin was compared to samples containing high percentages of Nigella Sativa.

\subsubsection{Fat}

In chocolate samples, fat increased with increasing levels of Nigella Sativa replacement in the samples. Samples containing 6 and 9\% levels of Nigella Sativa replacement did not show significant differences with each other. The percentage of fat in chocolate samples containing sorbitol replaced with sugar and the control sample was not significantly different and the amount of fat in these samples was measured 50.5 [11] reported that the use of inulin, polydextrose, and maltodextrin at different levels $(0,25,50$, 75 , and $100 \%$ ) in the production of low-calorie dark chocolate did not have a significant effect on the fat content of samples. In another study on the effect of D-tagatose and inulin as a substitute for sucrose on the physicochemical properties of milk chocolate, the results showed that there was a statistically significant difference between samples with different levels. There was no substitution of D-tagatose and inulin $(25,50,75$, and $100 \%)$ and the control sample in terms of fat content.

\subsubsection{Protein}

Protein levels in chocolate samples increased with increasing levels of Nigella Sativa substitution. Samples with levels of 3 and $6 \%$ Nigella Sativa replacement did not show significant differences with each other. Protein content in sorbitol-substituted chocolate samples with sugar and control samples was not significantly different and the protein content in these samples was 7.5. The results showed that by replacing sucrose with the sucralose-maltodextrin mixture in traditional rice bread pastry, the protein content of the control sample and the sample containing the sucralose-maltodextrin mixture did not change significantly (Kandahari Yazdi et al., 2016). Because Nigella Sativa contains significant amounts of protein, its replacement with maltodextrin in the chocolate formula has caused a significant increase in the amount of protein in chocolate samples.

\subsubsection{Carbohydrates}

In chocolate samples, carbohydrates showed a decreasing trend with increasing levels of Nigella Sativa substitution in the samples. Samples containing 3\% Nigella Sativa replacement and control samples did not show significant differences with each other. According to the results of some researchers, $23-28 \%$ of the dry weight of Nigella Sativa is carbohydrates [12]. Therefore, its presence in the chocolate formulation can affect the carbohydrate content of the final product, but since maltodextrin is also a polymer of polysaccharides, and contains a mixture of molecular weight compounds between polysaccharides and oligosaccharides its reduction in the formulation can have a positive effect on the carbohydrate content of samples., carbohydrate content in chocolate samples containing sorbitol replaced with sugar and control sample was not significantly different and the number of carbohydrates in these samples was measured 38.5.

\subsubsection{Ash}

The amount of ash in chocolate samples increased with increasing levels of Nigella Sativa replacement. Since Nigella Sativa is a rich source of minerals, its presence in chocolate formulations can have a significant effect on the ash content of samples. Samples with levels of 3 and $6 \%$ 
Nigella Sativa replacement did not show significant differences with each other. The amount of ash in the samples containing sorbitol replaced with sugar and the control sample did not show a significant difference and the amount of ash in these samples was measured equal to 4.2. by replacing part of the sugar with liquid date sugar, the ash content of walnut halva samples with date sugar replaced by liquid sugar increased significantly compared to the control sample. Because date liquid sugar contains high amounts of minerals including sodium, potassium, calcium, iron, magnesium, zinc, and phosphorus, as well as amounts of nitrogen due to protein. In another study examined the effect of sugar substitution with grape juice in the biscuit formula and concluded that this substitution in the formulation increases the ash percentage of the final product and the reason is that grape juice is rich in sodium, calcium, potassium, magnesium, iron, and phosphorus.

\subsection{The Effect of Sucrose Replacement with Sorbitol and Maltodextrin with Nigella Sativa on Chocolate Texture Hardness}

The amount of texture stiffness in the histometric test refers to the maximum height of the force curve at the first pressure, which indicates the maximum force applied during the biting operation. This index is related to the firmness or softness of the food and is greatly affected by the ability of water to bind to alcoholic sugars and its loss during storage. In dark chocolate, the hardness decreased and increased with increasing levels of sorbitol and Nigella Sativa substitution, respectively. In samples containing sorbitol replaced with sugar, the lowest sample hardness was at the level of $30 \%$ sorbitol replacement. The highest amount of hardness was observed in the control sample (100\% sucrose). The decrease in hardness in samples with higher sorbitol levels is due to the moisture absorption of this sugar substitute. Samples containing 3\% and $6 \%$ Nigella Sativa replacement did not show a significant difference with each other in terms of hardness and the sample containing 9\% Nigella Sativa replacement had the highest hardness. Maltodextrin has hydrophilic properties and one of the reasons for the reduction in hardness in samples with high ratios of maltodextrin (control sample and sample with levels of 3 and $6 \%$ Nigella Sativa replacement) is the presence of low molecular weight sugars in this compound which is very attractive. They are moist and increase the hardness of chocolate texture by increasing the absorption power of water the effect of fat substitution in biscuit formula and found that increasing the ratio of maltodextrin and polydextrose in the samples reduced their hardness due to the higher moisture content of the samples.

\subsection{The Effect of Sucrose Replacement with Sorbitol and Maltodextrin with Nigella Sativa on Chocolate Color}

As can be seen in Table 1, the brightness ( $\left.\mathrm{L}^{*}\right)$ increases significantly as the amount of sucrose replaced by sorbitol increases. In samples containing sorbitol replaced with sucrose, the amount of redness $\left(\mathrm{a}^{*}\right)$ and jaundice $\left(\mathrm{b}^{*}\right)$ decreased compared to the control sample. The decrease in color (increase in $\mathrm{L}^{*}$ index) of sorbitol-containing samples can be attributed to the lack of a functional group in this sugar and its inability to participate in Millard browning reactions. Replacing sucrose with erythritol at $75 \%$ and $100 \%$ concentrations showed a decrease in cake crust color, which is in line with the results of this study. In another study, the results showed that the replacement of sucrose with sorbitol and erythritol in the cake makes the color of the cake shell and core lighter than the control sample [13]. With increasing levels of maltodextrin replacement with Nigella Sativa, the amount $\left(\mathrm{L}^{*}\right)$ decreased significantly and the amount of redness $\left(a^{*}\right)$ and jaundice $\left(b^{*}\right)$ increased. Maltodextrin is a heavy molecular polysaccharide that has few reducing groups and reduces the rate of browning, caramelization, and Maillard reaction by decreasing water activity and increasing the percentage of dry matter [14].

Table 1. Comparison of the effect of sorbitol and Nigella Sativa alternatives on the color of dark chocolate samples.

\begin{tabular}{|c|c|c|c|c|c|c|c|c|}
\hline \multirow{2}{*}{$\begin{array}{l}\text { Sensory } \\
\text { properties }\end{array}$} & \multicolumn{4}{|c|}{ Nigella Sativa replacement levels (\%) } & \multicolumn{4}{|c|}{ Sorbitol replacement levels (\%) } \\
\hline & $\mathbf{0}$ & 3 & 6 & 9 & $\mathbf{0}$ & 10 & 20 & 30 \\
\hline $\mathrm{L}^{*}$ & $0.5 \pm 27.072 \mathrm{a}$ & $3.00 \pm 81.047 \mathrm{~b}$ & $1.0 \pm 13.019 \mathrm{c}$ & $1.0 \pm 21.065 \mathrm{c}$ & $1.0 \pm 13.072 \mathrm{c}$ & $2.0 \pm 99.047 b$ & $2.0 \pm 69.019 \mathrm{~b}$ & $4.0 \pm 5.065 \mathrm{a}$ \\
\hline$a^{*}$ & $0.0 \pm 10.072 b$ & $0.0 \pm 17.047 \mathrm{~b}$ & $1.0 \pm 18.065 \mathrm{a}$ & $1.0 \pm 39.016 \mathrm{a}$ & $1.0 \pm 25.072 \mathrm{a}$ & $0.0 \pm 15.047 \mathrm{~b}$ & $0.0 \pm 12.065 b$ & $0.0 \pm 10.016 b$ \\
\hline$b^{*}$ & $0.0 \pm 43.086 \mathrm{~b}$ & $0.0 \pm 47.068 \mathrm{~b}$ & $1.0 \pm 36.041 \mathrm{a}$ & $1.0 \pm 40.063 \mathrm{a}$ & $1.0 \pm 48.086 \mathrm{a}$ & $0.0 \pm 42.068 \mathrm{~b}$ & $0.0 \pm 47.041 \mathrm{~b}$ & $0.0 \pm 41.063 \mathrm{~b}$ \\
\hline
\end{tabular}

\subsection{The Effect of Sucrose Replacement with Sorbitol and Maltodextrin with Nigella Sativa on the Sensory Properties of Chocolate}

The results of sensory evaluation of chocolate samples are shown in Table 2. As can be seen, the samples containing different levels of sorbitol were replaced with sugar, and the control sample did not have any significant differences in terms of sensory characteristics including color, taste, mouthfeel, and general acceptability. Samples containing different levels of Nigella Sativa replaced with maltodextrin and control samples did not differ significantly in terms of color and taste, but there was a significant difference between them in terms of oral feeling and overall acceptability. Maltodextrin as a fat substitute has a mouthfeel similar to fat [15] thus reducing it by increasing the ratio of Nigella Sativa in chocolate formulation reduces the sensory score of samples containing different levels of Nigella Sativa and sample superiority. The witness has become sensory in the eyes of the evaluators. The results study on the production of low-calorie muffins using stevia and maltodextrin showed that with increasing the amount of stevia in the muffin formulation, the score of sensory parameters such as color, taste, texture, and general acceptance decreased significantly. $\neg$ dar had. However, increasing the amount of maltodextrin 
improved oral sensation and increased the overall acceptance of the samples.

Table 2. Comparison of the effect of sorbitol and Nigella Sativa alternatives on some sensory properties of dark chocolate samples.

\begin{tabular}{|c|c|c|c|c|c|c|c|c|}
\hline \multirow{2}{*}{ Sensory properties } & \multicolumn{4}{|c|}{ Nigella Sativa replacement levels (\%) } & \multicolumn{4}{|c|}{ Sorbitol replacement levels (\%) } \\
\hline & $\mathbf{0}$ & 3 & 6 & 9 & $\mathbf{0}$ & 10 & 20 & 30 \\
\hline Color & $4.0 \pm 16.81 \mathrm{a}$ & $4.0 \pm 0.05 \mathrm{a}$ & $4.0 \pm 0.071 \mathrm{a}$ & $4.0 \pm 0.73 a$ & $4.0 \pm 5.71 \mathrm{a}$ & $4.0 \pm 00.70 \mathrm{a}$ & $4.0 \pm 16.71 \mathrm{a}$ & $4.0 \pm 20.00 \mathrm{a}$ \\
\hline Taste & $3.0 \pm 85.71 \mathrm{a}$ & $3.0 \pm 66.70 \mathrm{a}$ & $3.0 \pm 66.74 \mathrm{a}$ & $3.0 \pm 33.78 \mathrm{a}$ & $4.0 \pm 50.71 \mathrm{a}$ & $4.0 \pm 66.71 \mathrm{a}$ & $4.0 \pm 33.75 \mathrm{a}$ & $4.0 \pm 66.70 \mathrm{a}$ \\
\hline Oral sensation & $4.0 \pm 89.71 \mathrm{a}$ & $3.0 \pm 33.70 \mathrm{~b}$ & $3.0 \pm 33.78 \mathrm{~b}$ & $2.0 \pm 16.80 \mathrm{c}$ & $4.0 \pm 00.70 \mathrm{a}$ & $4.0 \pm 16.00 \mathrm{a}$ & $4.0 \pm 00.78 \mathrm{a}$ & $4.0 \pm 10.83 a$ \\
\hline General acceptance & $4.0 \pm 66.75 \mathrm{a}$ & $3.0 \pm 46.70 \mathrm{~b}$ & $3.0 \pm 33.79 \mathrm{~b}$ & $2.0 \pm 13.75 \mathrm{c}$ & $4.0 \pm 66.75 \mathrm{a}$ & $4.0 \pm 50.71 \mathrm{a}$ & $4.0 \pm 50.81 \mathrm{a}$ & $4.0 \pm 47.71 \mathrm{a}$ \\
\hline
\end{tabular}

\section{Conclusion}

According to the results of this study, sorbitol and Nigella Sativa had different effects on the chemical, textural, and sensory properties of low-calorie dark chocolate samples. The results of the present study showed that the replacement of sugar with different levels of sorbitol, despite not having a significant effect on the amount of fat, protein, carbohydrate, and ash, leads to a significant reduction in texture hardness. Among the tested samples, the sample with 3\% replacement of maltodextrin with Nigella Sativa, in the major sensory parameters of color and taste and indices $\mathrm{L}^{*}, \mathrm{a}^{*}$ and $\mathrm{b}^{*}$ did show a significant difference with the control sample and from consumers, It was more desirable. In general, using the findings of the present study, low-calorie dark chocolate can be produced that has the same chemical, textural and sensory properties as the sample prepared with sugar, while the presence of Nigella Sativa in the chocolate formulation as a source. Rich in protein, minerals, and essential fatty acids, it can meet the micronutrients needed by the body.

\section{References}

[1] Ronda F, Gamez M, Blanco CA and Caballero PA, 2005. Effects of polyols and non-digestible oligosaccharides on the quality of sugar-free sponge cakes, Food Chemistry 90 (4): 549-555.

[2] Devereux. H. M, Jones. G. P, McCormax. L, Hunter. W. C. 2003. Consumer Acceptability of low fat Foods Containing Inulin and Oligofructose. J. of Food Science, ol. 68, Nr. 5.1850-1854.

[3] Sudha ML, Srivastava AK, Vetrimani R, Leelavathi K. Fat replacement in soft dough biscuits: its implications on dough rheology and biscuit quality. J Food Eng 2007; 80: 922-930.

[4] Bolenz. S, Amtsberg. K and Schape. R. 2006. The broader usage of sugars and fillers in milk chocolate made possible by the new EC cocoa directive. International Journal of Food Science and Technology, 41: 45-55.
[5] Pasha I, Butt MS, Anjum FM and Shahzadi N, 2002. Effect of dietetic sweeteners on the quality of cookies, International Journal of Agriculture and Biology 4: 245-248.

[6] Keogh MK, Murray CA, O Kennedy BT. Effect of selected properties of ultrafiltered spray-dried milk powders on some properties of chocolate. Intl Dairy J. 2003; 13: 719-726.

[7] Anonymous. Position of the american dietetic association: Use of nutritive and nonnutritive sweeteners. Journal of the American Dietetic Association. Nr. 104, Vol. 2, pp: 255-275, 2004.

[8] Cheik-Roubou, S., S., Besbes, B., Hentati, C., Blecker, and C., Deroanne. 2007. Nigella Sativa L: chemical composition and physiochemical characteristics of lipid fraction. Food chemistry. J. 101 (2): 673-681.

[9] Atta, M. B., 2003. Some characteristics of (Nigella Sativa L.) Seed cultivated in Egept and its lipid profile. Food chemistry. J. 83 (1): 63-68.

[10] Ramadan MF, Morsel JT. Characterization of hospholipids composition of black cumin (Nigellasativa L.) seed oil. Nahrung 2002; 46: 240-4.

[11] Whelan AP, Vega C, Kerry JP, Goff HD. Physicochemical and sensory optimisation of a lowglycemic index ice cream formulation. Int J Food Sci Technol 2008; 43: 1520-7.

[12] Nebesny E, Żyżelewicz D, Motyl I, Libudzisz Z. Properties of sucrose-free chocolates enriched with viable lactic acid bacteria. Eur Food Res Technol 2005; 220: 358-62.

[13] Lin SD, Hwang CF and Yeh CH, 2003. Physical and sensory characteristics of chiffon cake prepared with erythritol as replacement for sucrose, Journal of Food Science 68 (6): 2107-2110.

[14] Docik-Baucal L, Dokic P, Jakovljevic J, 2004. Influence of different maltodextrins on properties of $\mathrm{O} / \mathrm{W}$ emulsions. Food Hydrocoll 18: 233-239.

[15] Hussein EA, El-BeltagyAE, Gaafor AM, 2011. Production and Quality Evaluation of low calorie cake. American Journal of Food Technology 6 (9): 827-834. 